\title{
Internal plasma potential measurements of a Hall thruster using xenon and krypton propellant
}

\author{
Jesse A. Linnell ${ }^{a)}$ and Alec D. Gallimore \\ Plasmadynamics and Electric Propulsion Laboratory, Department of Aerospace Engineering, \\ University of Michigan, 1919 Green Road B107, Ann Arbor, Michigan 48109
}

(Received 1 May 2006; accepted 19 July 2006; published online 11 September 2006)

\begin{abstract}
For krypton to become a realistic option for Hall thruster operation, it is necessary to understand the performance gap between xenon and krypton and what can be done to reduce it. A floating emissive probe is used with the Plasmadynamics and Electric Propulsion Laboratory's High-speed Axial Reciprocating Probe system to map the internal plasma potential structure of the NASA-173Mv1 Hall thruster [R. R. Hofer, R. S. Jankovsky, and A. D. Gallimore, J. Propulsion Power 22, 721 (2006); 22, 732 (2006)] using xenon and krypton propellant. Measurements are taken for both propellants at discharge voltages of 500 and $600 \mathrm{~V}$. Electron temperatures and electric fields are also reported. The acceleration zone and equipotential lines are found to be strongly linked to the magnetic-field lines. The electrostatic plasma lens of the NASA-173Mv1 Hall thruster strongly focuses the xenon ions toward the center of the discharge channel, whereas the krypton ions are defocused. Krypton is also found to have a longer acceleration zone than the xenon cases. These results explain the large beam divergence observed with krypton operation. Krypton and xenon have similar maximum electron temperatures and similar lengths of the high electron temperature zone, although the high electron temperature zone is located farther downstream in the krypton case.
\end{abstract}

(C) 2006 American Institute of Physics. [DOI: 10.1063/1.2335820]

\section{INTRODUCTION}

Hall thrusters are space propulsion devices that use crossed electric and magnetic fields to ionize and accelerate propellant atoms to high exhaust velocities. The strong magnetic field impedes the motion of the electrons establishing an electric field. The orthogonal electric and magnetic fields cause the electrons to follow an azimuthal closed drift path, and for this reason Hall thrusters are often referred to as closed-drift thrusters. Noble gases of high atomic weight, such as xenon and krypton, are the most common choice of propellant due to their high molecular weight and low ionization potential.

Due to the relative high price and scarcity of xenon and the superior specific impulse of krypton, krypton has recently sparked interest in the electric propulsion community. Even for small-scale missions, the financial savings in propellant cost can be tens of thousands of dollars given krypton's high specific impulse and low price. Although krypton's relatively smaller atomic mass results in higher specific impulses, krypton performance is hurt by its higher ionization potential. While previous studies ${ }^{1-5}$ report krypton to have an inferior performance as compared to xenon, recent results using the NASA- $457 \mathrm{M}^{6}$ and the NASA- $400 \mathrm{M}^{7}$ indicate that krypton can be operated at efficiencies comparable to xenon. Before krypton can become a legitimate option for space propulsion, the reasons for the krypton efficiency gap must be fully understood and the efficiency gap must be reduced.

Previous researchers ${ }^{2,3,7}$ have concluded that the dominant contributing factor to krypton's inferior efficiency is propellant utilization. It has recently been shown that beam

\footnotetext{
${ }^{a)}$ Electronic mail: jlinnell@umich.edu.
}

divergence is also a significant contributor to the kryptonxenon efficiency gap. ${ }^{8}$ To obtain a greater understanding of the krypton-xenon efficiency gap, it will be necessary to collect information about the plasma behavior internal to the Hall thruster discharge channel.

Internal floating emissive probe measurements have been conducted for the NASA-173Mv1 operating with xenon and krypton and are reported below. The floating emissive probe is mounted on the Plasmadynamics and Electric Propulsion Laboratory (PEPL) High-Speed Axial Reciprocating Probe (HARP) system, which sweeps the emissive probe into the thruster discharge channel and provides a map of the internal plasma potential structure. Similar methods of characterizing the internal potential structure of Hall thrusters have been used by other researchers. ${ }^{9-14}$ In addition to the plasma potential, the electron temperature and electric-field maps are also extracted from the data. For both krypton and xenon, the Hall thruster is operated at discharge voltages of 500 and $600 \mathrm{~V}$. High-voltage operation is chosen because a krypton Hall thruster would most likely operate in a way that decreases krypton's performance gap and benefits from krypton's superior specific impulse. ${ }^{15}$

\section{EXPERIMENTAL SETUP AND APPARATUS}

\section{A. Experimental setup}

The measurements reported in this paper were conducted in the Large Vacuum Test Facility (LVTF) at PEPL. The LVTF is a cylindrical stainless-steel tank that is $9 \mathrm{~m}$ long and $6 \mathrm{~m}$ in diameter. The vacuum chamber operates at a base pressure of $1.5 \times 10^{-7}$ torr and approximately 3.3 $\times 10^{-6}$ torr during all thruster operating points. 


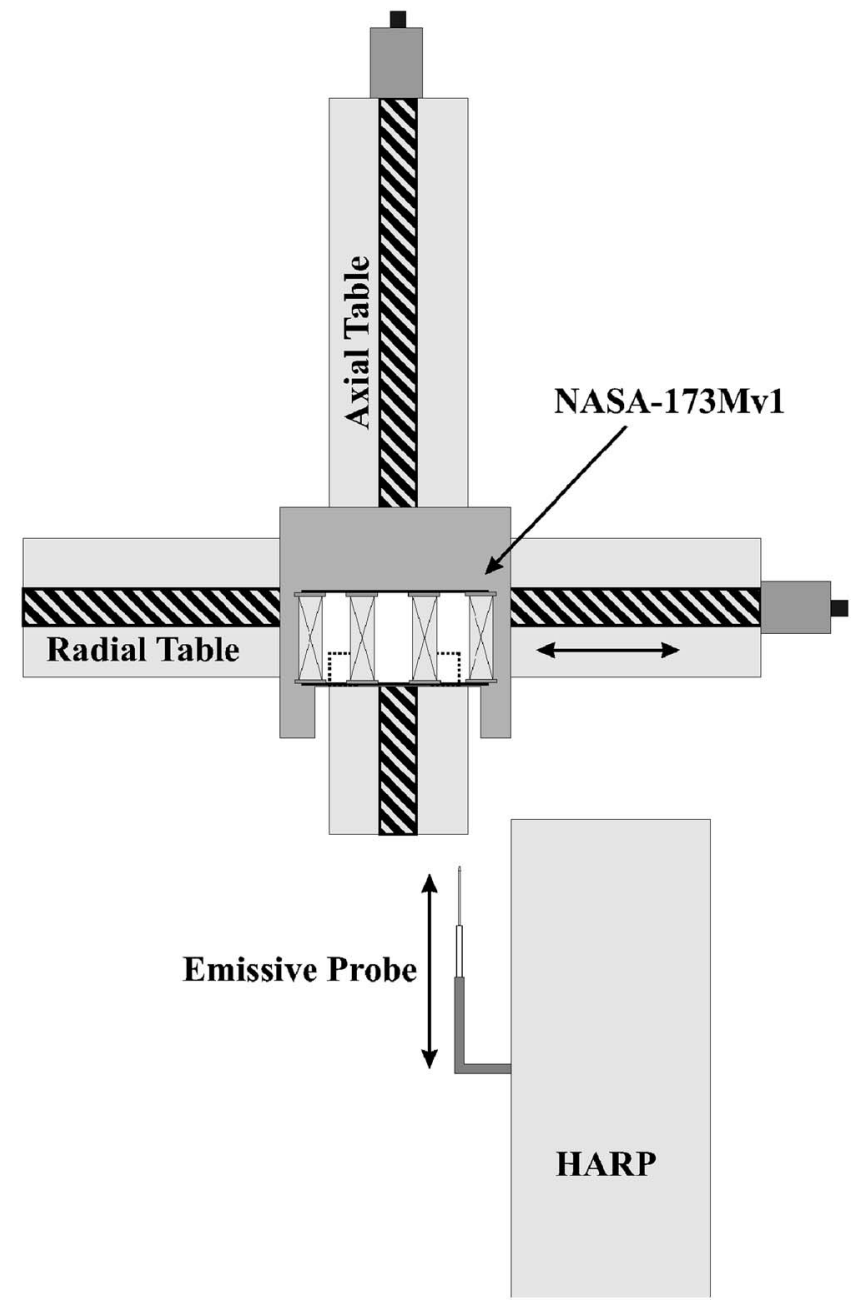

FIG. 1. Internal floating emissive probe experimental setup.

As shown in Fig. 1, the NASA-173Mv $1^{16-18}$ is mounted on two linear (radial and axial) tables that control the probe alignment and positioning. The NASA-173Mv1 Hall thruster (Fig. 2) is used for all measurements. In addition to the standard inner and outer magnetic coils, the NASA-173Mv1 uses a trim coil to shape the magnetic-field topology. The trim coil creates an electrostatic plasma lens ${ }^{16,19-23}$ and a magnetic mirroring effect that focus the electrons and ions toward the center of the discharge channel. ${ }^{14,24}$ This effect can be explained because to first order the magnetic-field lines chart the equipotential lines inside a Hall thruster. ${ }^{22,25}$ The thruster is operated for one hour for initial conditioning and is warmed up for at least $30 \mathrm{~min}$ at a given operation point before data are taken. A Busek BHC-50-3UM hollow cathode is used for all measurements.

The emissive probe is mounted on the HARP system, ${ }^{26,27}$ which is securely fixed downstream of the thruster to dampen any vibrations caused by the high acceleration of the probe. The HARP has a linear motor assembly providing direct linear motion at very high speed and large acceleration.

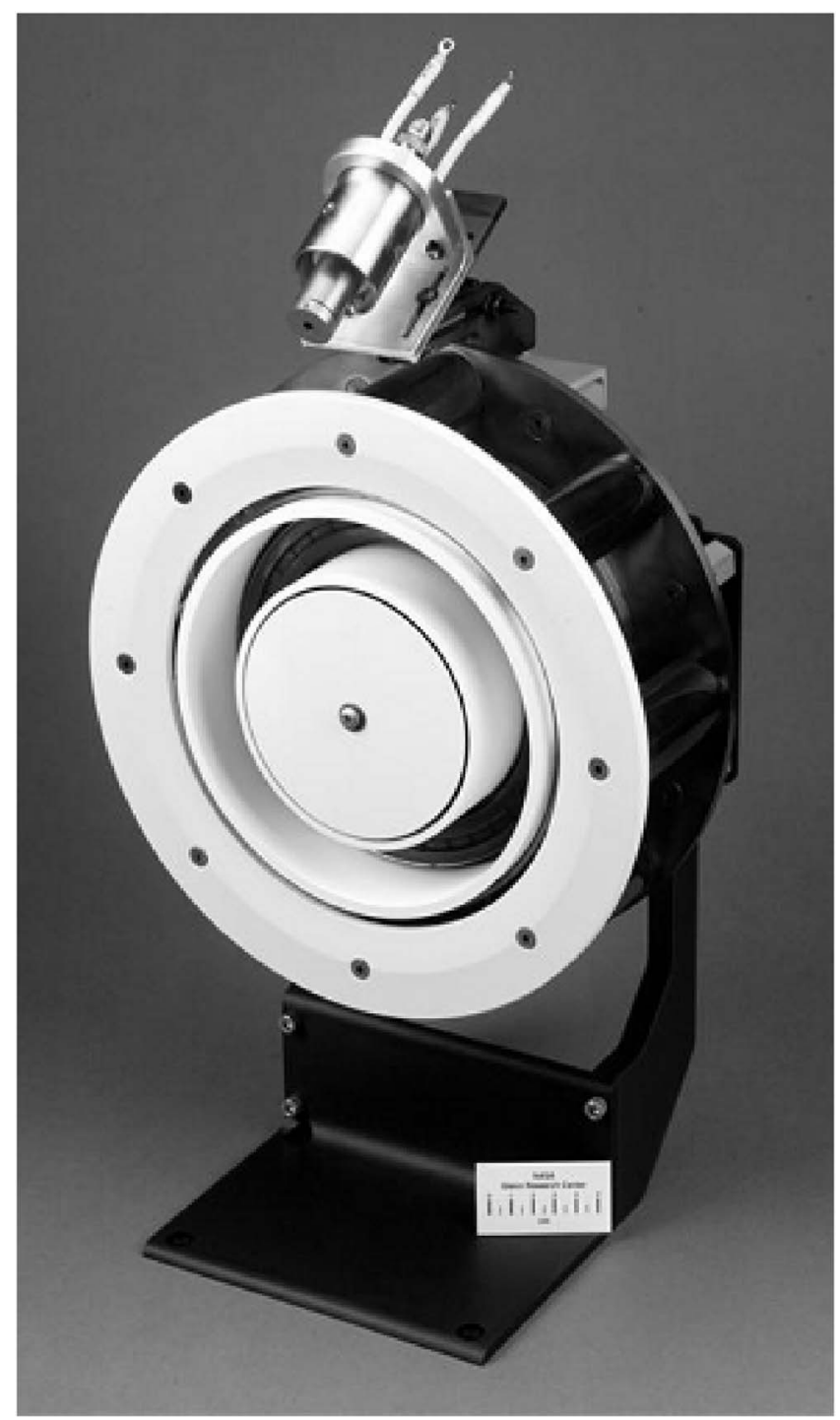

FIG. 2. NASA-173Mv1 Hall thruster.

\section{B. Emissive probe \\ 1. Probe description}

The emissive probe is composed of 1.5 -mm-diam double bore alumina insulator. The emitting filament is $1 \%$ thoriated tungsten with a diameter of $0.0127 \mathrm{~cm}$. The NASA-173Mv1 has a maximum magnetic field of approximately $250 \mathrm{G}$, resulting in an electron gyroradius inside the Hall thruster that is smaller than the diameter of the emitting filament. This condition is necessary for unmagnetized probe theory to be valid. ${ }^{28} \mathrm{~A}$ schematic of the emissive probe design appears in Fig. 3.

The area mapped by the emissive probes is displayed in Fig. 4. The origin is taken to be the location where the inner wall meets the anode. Five axial sweeps spaced $5 \mathrm{~mm}$ apart are taken inside the Hall thruster discharge channel and data are shown for the region between 10 and $100 \mathrm{~mm}$ from the anode. The emissive probe is positioned so that the plane of the filament loop is normal to the thruster radial direction. The expected resolution of the emissive probe is $1.5 \mathrm{~mm}$, which is the approximate size of the filament loop. For this 


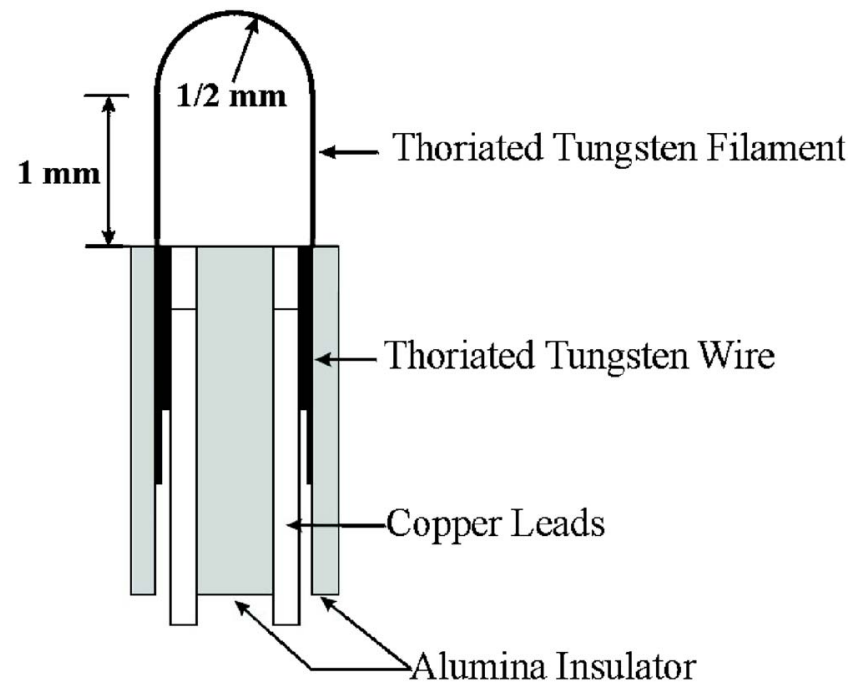

FIG. 3. Emissive probe schematic.

experiment, the probe is swept at $150 \mathrm{~cm} / \mathrm{s}$ and residence time inside the discharge channel is kept under $80 \mathrm{~ms}$.

The floating emissive probe circuit consists of the emissive probe, an isolation amplifier, and a floating power supply capable of supplying enough current to heat the filament (3-4 A). The floating emissive probe circuit is shown in Fig. 5. The sampling rate is set to sample every $0.5 \mathrm{~mm}$, which results in aliasing of the signal so that high-frequency oscillations cannot be resolved. Therefore, the data presented constitute "time-averaged" measurements. The perturbations to the discharge current and cathode potential are also recorded. During post processing, a gentle spline smoothing ${ }^{29}$ is used to reduce the signal noise from the probe position and the floating probe potential. Examples of a typical data sweep are given in Fig. 6, which shows the floating potential and the perturbations to the thruster as the probe is swept into the discharge channel. In this figure $V_{p}$ is the plasma potential, $V_{k}$ is the cathode potential, and $I_{D}$ is the discharge current. For the reported data, the perturbations to the discharge current are below 15-20\%.

\section{Space-charge limited sheath correction}

Space-charge effects must be taken into account when analyzing emissive probe data in Hall thrusters. The spacecharge limit is reached when the emitted electron current to

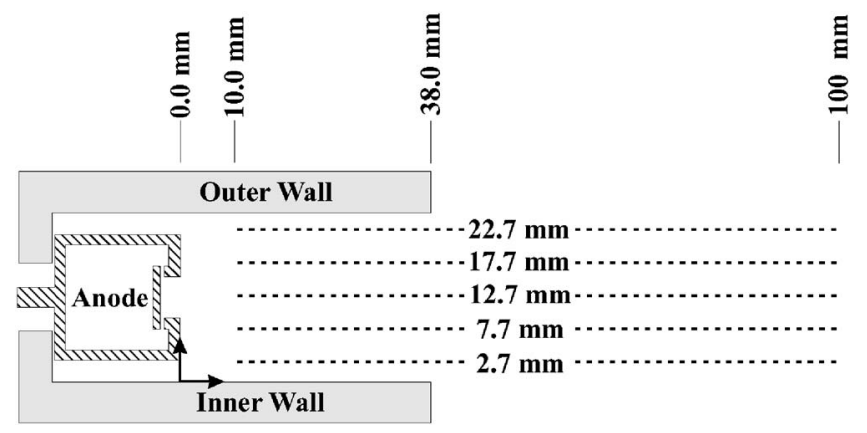

FIG. 4. Emissive probe mapping region.

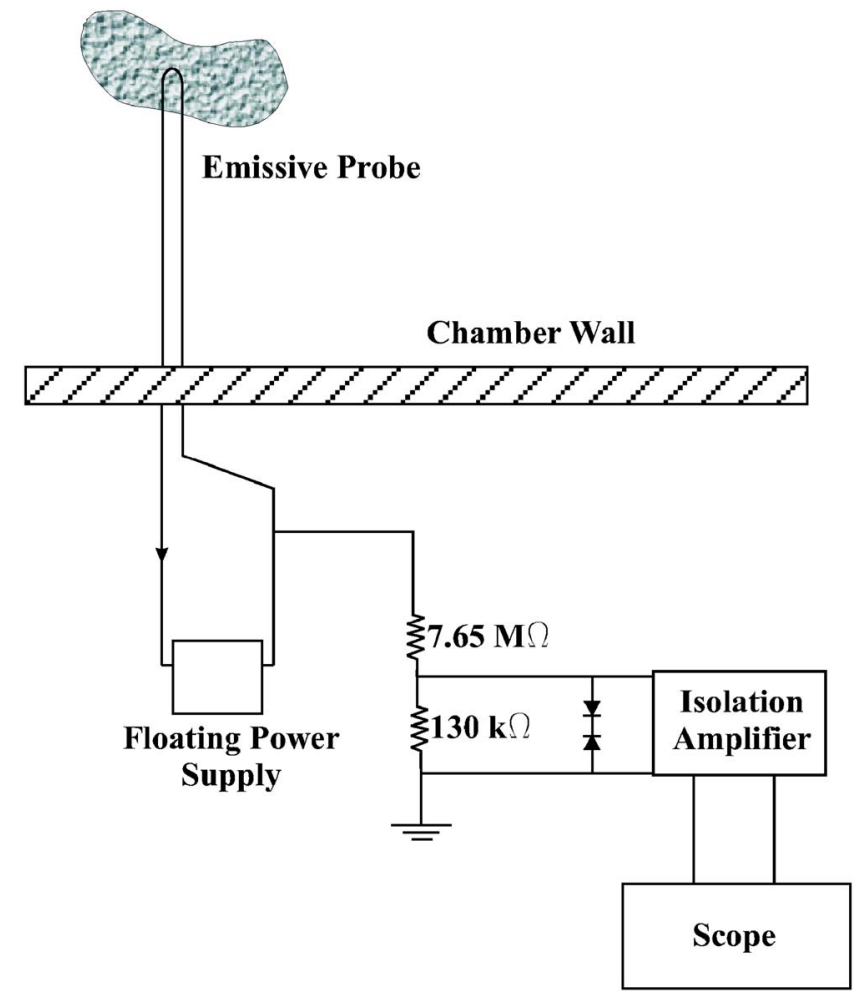

FIG. 5. Floating emissive probe circuit.

collected electron current ratio reaches a critical value that is approximately equal to $1 .^{30}$ Above this critical ratio, a potential well forms and emitted electrons are returned to the probe, creating a double sheath.

The space-charge limited sheath surrounding the emissive probe appears in Fig. 7. For the following discussion, the probe sheath is separated into two sections: the collector sheath and the presheath. Three lines representing possible collector sheaths appear in Fig. 7: (i) $\delta<\delta_{c}$, insufficiency electron emission; (ii) $\delta=\delta_{c} \approx 1$, space-charge limited regime; and (iii) $\delta \gg 1$, very strong electron emission. ${ }^{31}$ Due to the extreme frailty of the emissive probe inside the harsh Hall thruster discharge channel environment, the heater current is slowly increased until adequate filament heating is

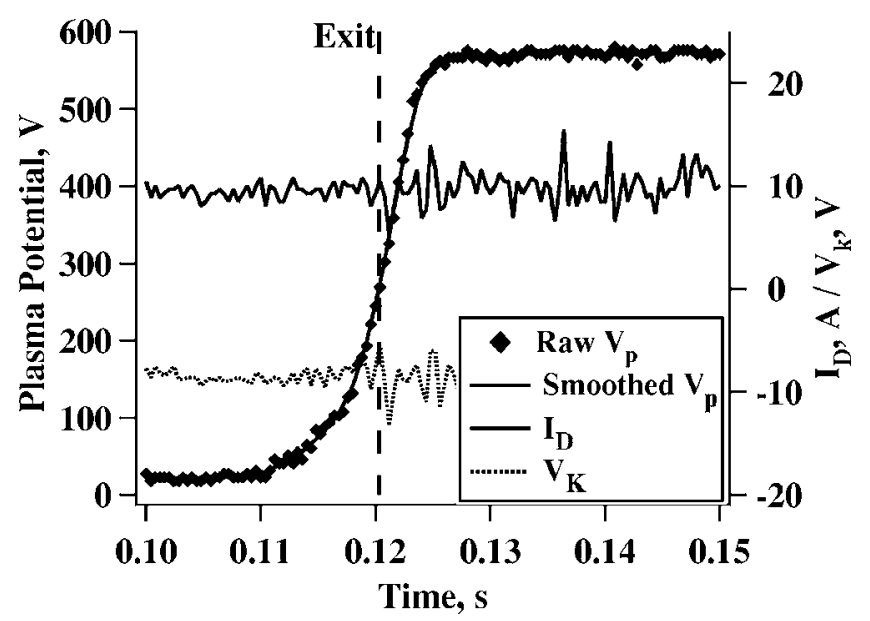

FIG. 6. Emissive probe sweep example. 


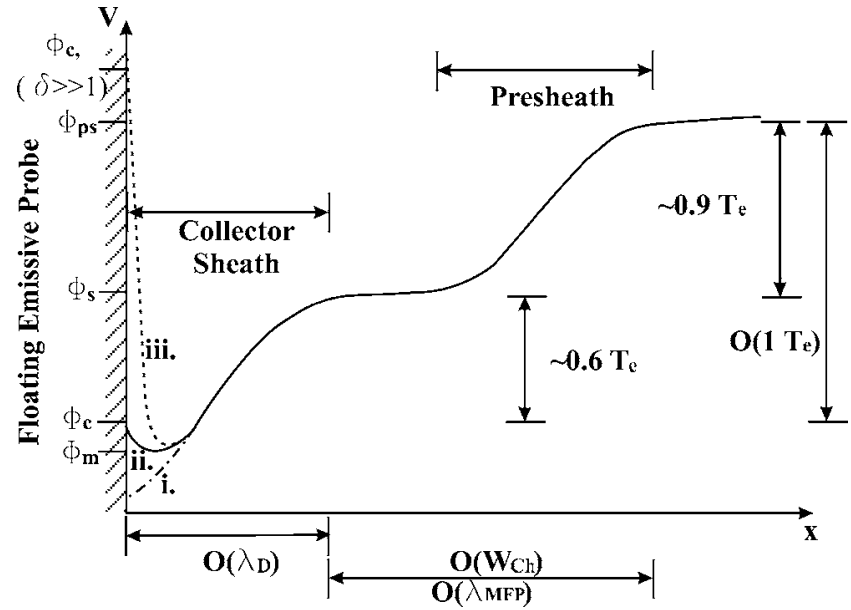

FIG. 7. Emissive probe sheath. The different operation regimes are shown by dashed lines and are labeled accordingly. (Not to scale.)

reached. Adequate heating is reached when the plasma potential profile no longer changes with increased electron emission and the probe enters the space-charge limited regime. If electron emission is increased further, it is possible for the probe to enter regime (iii) (shown in Fig. 7). This is an extreme case in which very high electron emission results in probe voltages greater than plasma potential. However, given the conditions typical of a Hall thruster, operation in this regime is unlikely. ${ }^{32}$

In order to correct for the space-charge limited sheath, the measured plasma potential is augmented by adding the potential drop across the collector sheath $\left(0.6 T_{e}\right){ }^{14,30,33}$ This yields the instantaneous plasma potential local to the emissive probe while avoiding added complication from trying to correct for the large presheath. The collector sheath size $\left[\sim \mathrm{O}\left(\lambda_{D}\right)\right]$ internal to the Hall thruster is on the same order as the wire diameter, which is an order of magnitude smaller than the total emitting tip dimensions. Therefore, the desired resolution of approximately $1.5 \mathrm{~mm}$ is maintained. Because of the presheath size is on the same order as the discharge channel width, ${ }^{34}$ it is difficult to account for the presheath potential drop while maintaining a meaningful spatial resolution. The potential drop across the presheath $\left(0.9 T_{e}\right)^{33}$ is considered a perturbation to the plasma and is used to define error bars for the measurement. In addition to the presheath perturbation, one half of the potential drop across the floating heater power supply should also be included as uncertainty. The heater filament potential drop is $4 \mathrm{~V}$. Therefore, total error associated with the plasma potential measurements is equal to $\pm 0.9 T_{e}-2 \mathrm{~V}$.

\section{Electron temperature and electric-field calculation}

Electron temperature can be calculated by using both "hot" and "cold" probe measurements. ${ }^{11}$ Cold measurements refer to measurements taken with no filament heating. Equation (1) uses the potential drop across the collector sheath and presheath to calculate the electron temperature. By using this equation, it is assumed that the reported plasma potential (corrected only for the collector sheath) is an accurate measurement of the true plasma potential. Neglecting to correct for the presheath may introduce an inconsistency with this method, but does not change the main conclusions of this paper. In Eq. (1), $k_{B}$ is the Boltzmann constant, $T_{e}$ is the electron temperature, $V_{f}$ is the cold probe floating potential, and $e$ is the electron charge. The error in the temperature calculation is estimated to be $-1 /+38 \%$. $^{11}$

$$
V_{p}-V_{f}=-\frac{k_{B} T_{e}}{e} \ln \left(0.61 \sqrt{\frac{2 \pi m_{e}}{M_{i}}}\right) .
$$

Axial and radial electric fields at each location inside the thruster are also presented below. A central difference method is used with the plasma potentials to calculate the electric field. The forward difference technique is used for the first point, and the backward difference approach for the last point.

\section{RESULTS AND DISCUSSION}

The Hall thruster operating conditions for the internal emissive probe measurements are given in Table I. Measurements are taken with xenon at discharge voltages of 500 and $600 \mathrm{~V}$ and an anode flow rate of $10 \mathrm{mg} / \mathrm{s}$. Corresponding krypton points are taken that match the power levels of the xenon points. The magnetic coil settings for these operation points were found in a previous experiment by calculating real-time thruster efficiencies as a function of thruster settings. The optimum magnetic currents are found when the efficiency is maximized and not when discharge current is minimized. Therefore, each operation point has it own unique and optimized magnet settings. It should be noted that the magnetic-field topology strongly affects internal features such as the acceleration zone location and dimensions, and the location of the maximum electron temperature. For this reason, any differences in internal features between xenon and krypton operation will always be strongly tied to the different magnetic-field topologies. With this said, the focus of this experiment is to study optimized xenon/krypton performance, not to match the magnetic-field topology.

TABLE I. Thruster operating conditions.

\begin{tabular}{ccccccccccc}
\hline \hline $\begin{array}{c}\text { Point } \\
\text { no. }\end{array}$ & Propellant & $\begin{array}{c}V_{k} \\
(\mathrm{~V})\end{array}$ & $\begin{array}{c}V_{d} \\
(\mathrm{~V})\end{array}$ & $\begin{array}{c}I_{d} \\
(\mathrm{~A})\end{array}$ & $\begin{array}{c}\text { Anode } \\
\text { Flow }(\mathrm{mg} / \mathrm{s})\end{array}$ & $\begin{array}{c}\text { Cathode } \\
\text { Flow }(\mathrm{mg} / \mathrm{s})\end{array}$ & $\begin{array}{c}\text { Inner } \\
\text { Coil (A) }\end{array}$ & $\begin{array}{c}\text { Outer } \\
\text { Coil (A) }\end{array}$ & $\begin{array}{c}\text { Trim } \\
\text { Coil (A) }\end{array}$ & $\begin{array}{c}\text { Anode } \\
\text { Effic. }(\%)\end{array}$ \\
\hline 1 & Xenon & -11.7 & 500 & 9.27 & 10.00 & 1.00 & 2.90 & 2.87 & -0.87 & 66.1 \\
2 & Xenon & -12.3 & 600 & 9.59 & 10.00 & 1.00 & 3.17 & 3.42 & -1.08 & 63.8 \\
3 & Krypton & -14.4 & 500 & 9.27 & 7.77 & 0.78 & 1.79 & 2.27 & -0.43 & 56.6 \\
4 & Krypton & -13.3 & 600 & 9.59 & 7.80 & 0.78 & 1.98 & 2.18 & -0.46 & 54.9 \\
\hline \hline
\end{tabular}


a) $\mathrm{Xe}$

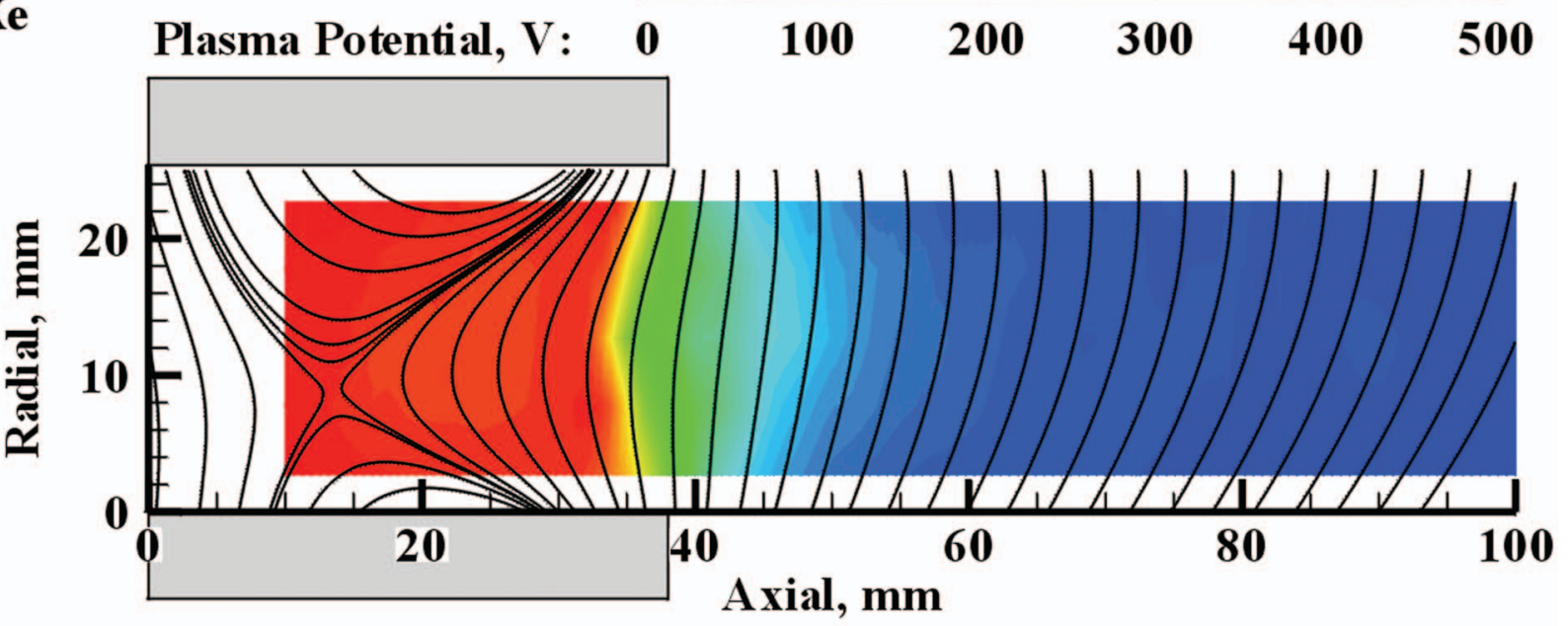

b) $\mathbf{K r}$
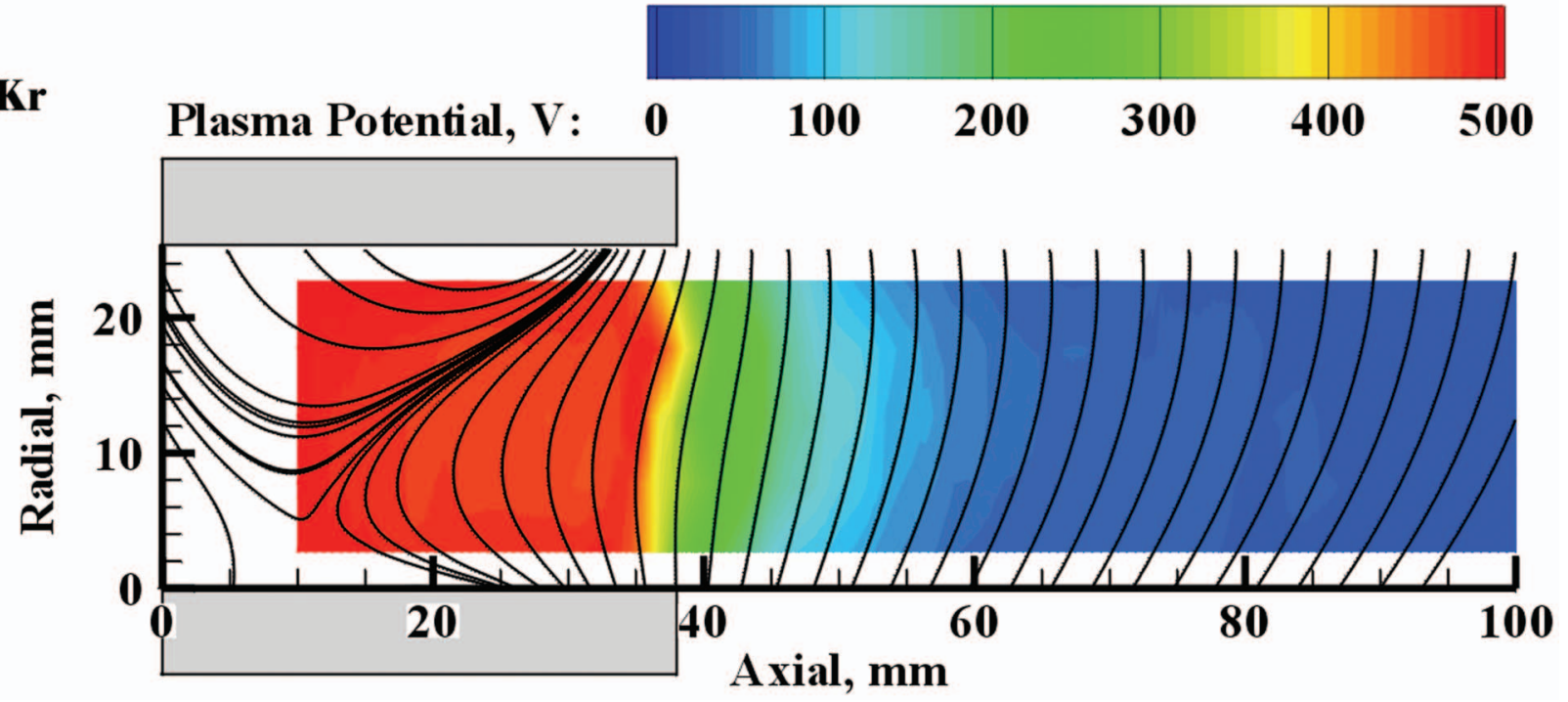

FIG. 8. (Color) Plasma potential map for xenon (a) and krypton (b) at a discharge voltage of $500 \mathrm{~V}$.

For each operating condition, the plasma potential, electron temperature, axial electric field, and radial electric field are given. In the following maps, the magnetic-field topology path lines are overlaid with the plasma potential. The magnetic fields have been calculated using the 3D magnetostatic solver Magnet 6.0 by Infolytic.

\section{A. 500-V comparison}

The internal plasma potential map for xenon and krypton at $500 \mathrm{~V}$ is shown in Fig. 8. These cases show a strong correlation between the magnetic-field lines and the plasma potential. The xenon case displays a strong focusing in the equipotential lines that is due to the plasma lens established by the magnetic circuit. This behavior is also demonstrated computationally by Keidar. ${ }^{35}$ However, the krypton equipotential lines have less of a concave shape and are actually defocusing. This result is consistent with plume measurements that show krypton having a larger beam divergence than xenon. ${ }^{8}$ The differences in the shape of xenon and krypton equipotential lines are strongly related to their different magnetic-field topologies. Krypton operation requires lower magnet currents to achieve optimum efficiency and utilizes a weaker plasma lens. Efficiency optimization for the krypton data points is strongly connected to maximizing propellant utilization. ${ }^{8}$ With propellant utilization being such an important focus of optimization, other efficiency components (such as beam divergence) suffer.

Electron temperature mapping for the $500-\mathrm{V}$ cases is shown in Fig. 9. There is a region of high electron temperature that begins immediately upstream of the acceleration zone and continues into the acceleration zone. This region is similar in dimension and magnitude for both propellants, although in the krypton case the acceleration zone starts slightly farther downstream. The maximum electron temperature of both xenon and krypton cases reaches approximately $50 \mathrm{eV}$, although there is one "hot" spot in the krypton 
(a) $\mathbf{X e}$

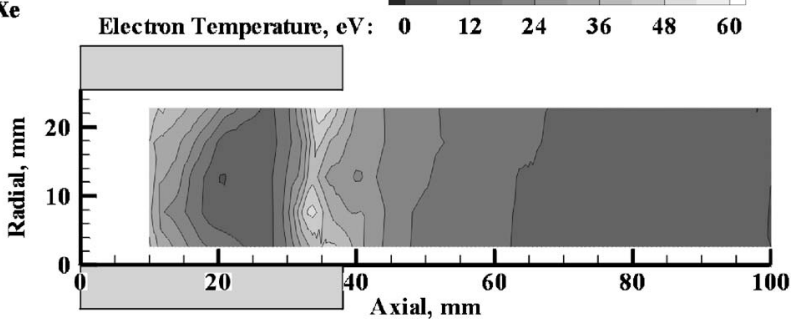

(b) $\mathbf{K} \mathbf{r}$

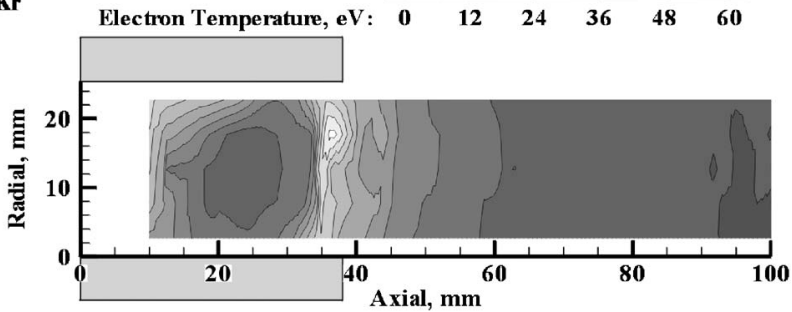

FIG. 9. Electron temperature map for xenon (a) and krypton (b) at a discharge voltage of $500 \mathrm{~V}$.

case that reaches $60 \mathrm{eV}$. This "hot" spot is also observed with internal Langmuir probe measurements for the same operating conditions. ${ }^{24}$

There is also an additional region of high electron temperature near the anode, which is comparable in magnitude to the "hot" region near the acceleration zone. This nearanode "heating" is unexpected, although a similar trend is observed by Meezan et al. ${ }^{10}$ However, subsequent internal Langmuir probe measurements do not show this near-anode hot zone. ${ }^{9}$ The cold probe measurements used to calculate the electron temperature [Eq. (1)] measured an artificial drop in floating potential not observed in the Langmuir probe floating potential. The source of this anode heating is not entirely clear, although the magnetic field can cause a significant change on the probe collection area and the electron dynamics near the probe. The near-anode heating is extremely well correlated with a decrease in the radial component of the magnetic field and with magnetic-field lines that are predominantly axial. When the radial component approaches zero Gauss, the electron current appears to be enhanced resulting in a decreased floating potential measurement. However, this error in electron temperature is only a concern near the anode, and the electron temperatures elsewhere in the discharge channel are more reliable.

Axial electric fields are shown in Fig. 10, which shows the longer acceleration zone in the krypton case. For xenon, the maximum electric field reaches approximately $70 \mathrm{~V} / \mathrm{mm}$. For krypton, the maximum axial electric field is also approximately $70 \mathrm{~V} / \mathrm{mm}$, but extends over a thin region in the acceleration zone. Figure 10 also shows that both cases display a potential well downstream of the main acceleration zone. This can be seen as a dark spot in the middle of the mapped area between the axial locations of 40-45 $\mathrm{mm}$. This potential well has also been observed by other researchers. $9,36,37$

Radial electric fields can be seen in Fig. 11. Xenon's beam focusing and krypton's defocusing are well illustrated (a) $\mathbf{X e}$

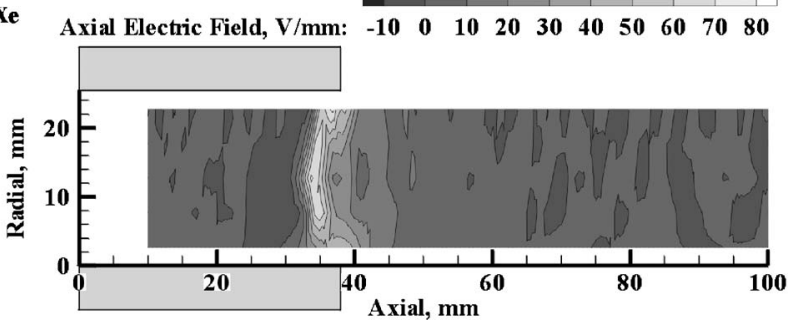

(b) $\mathbf{K r}$

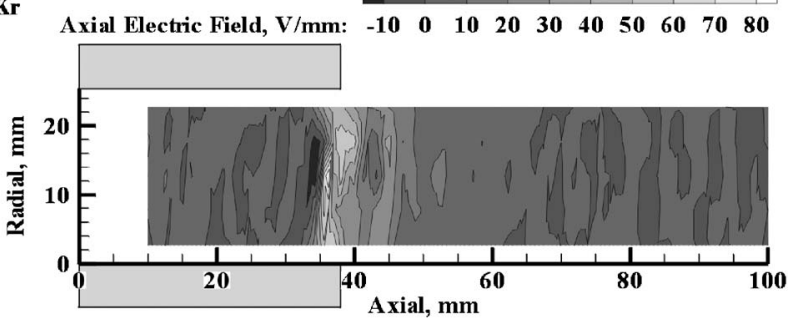

FIG. 10. Axial electric-field map for xenon (a) and krypton (b) at a discharge voltage of $500 \mathrm{~V}$.

by the compression and expansion points near the channel walls and exit. The maximum radial electric fields are approximately $20 \%$ of the maximum axial electric field for both xenon and krypton. The xenon focusing occurs just inside the discharge channel, but the krypton defocusing begins at the exit and continues downstream. The findings suggest that there may not be an appreciable difference in wall losses and erosion for krypton and xenon.

\section{B. 600-V comparison}

As in the 500- $\mathrm{V}$ cases, the $600-\mathrm{V}$ data show an excellent correspondence between the magnetic-field path lines and the equipotential lines (Fig. 12). Again, this correlation between equipotential lines and magnetic-field path lines re-

(a) $\mathbf{X e}$

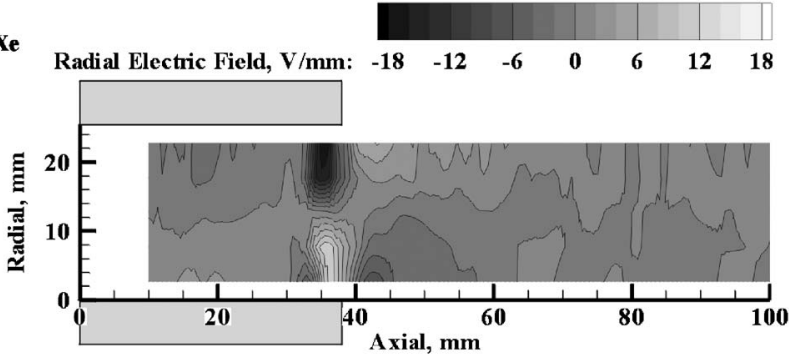

(b) $\mathbf{K r}$

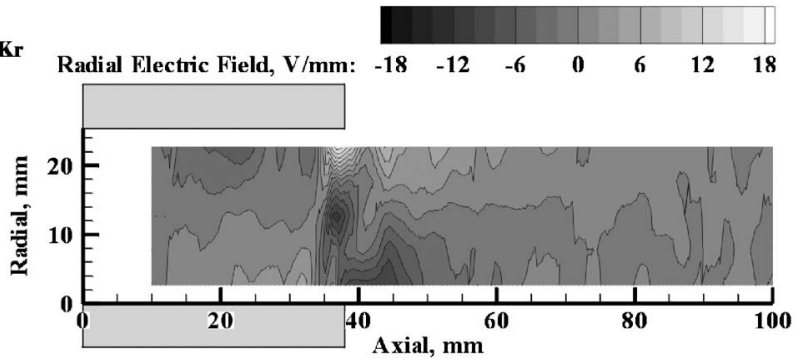

FIG. 11. Radial electric-field map for xenon (a) and krypton (b) at a discharge voltage of $500 \mathrm{~V}$. 
a) $\mathrm{Xe}$

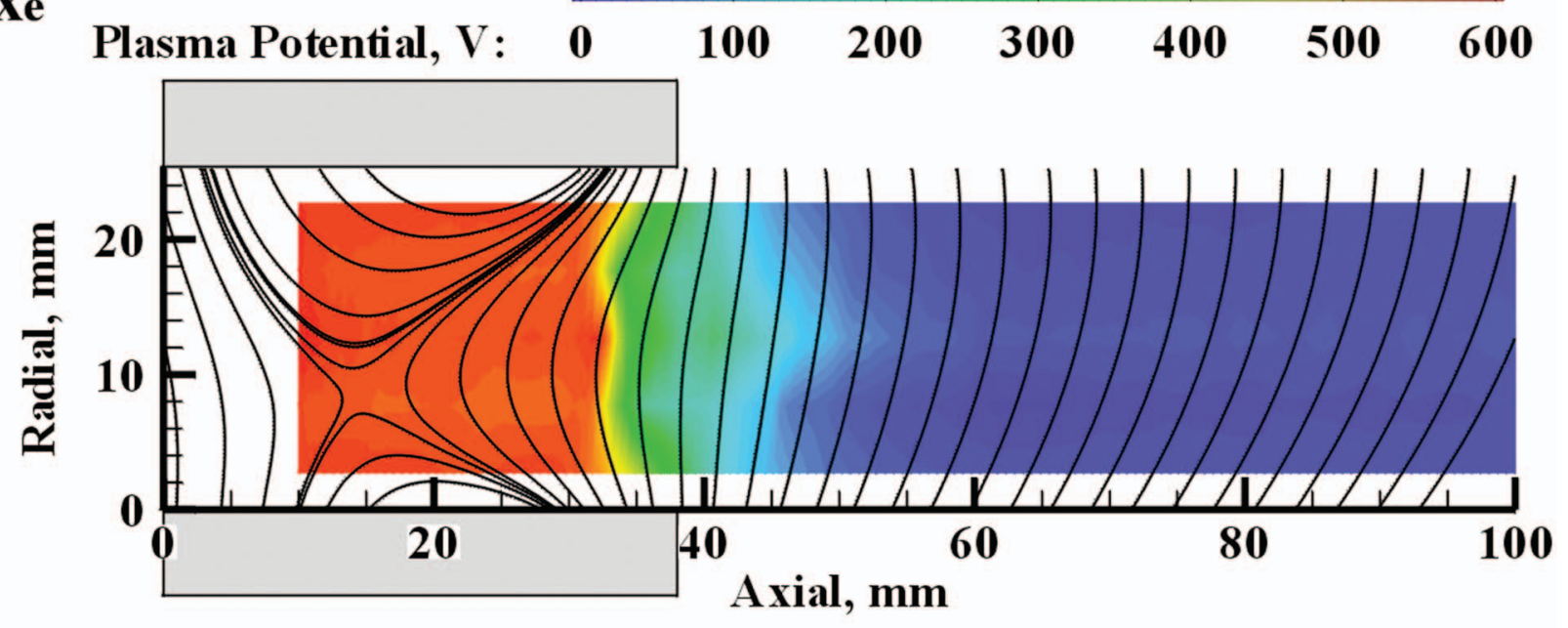

b) $\mathbf{K r}$

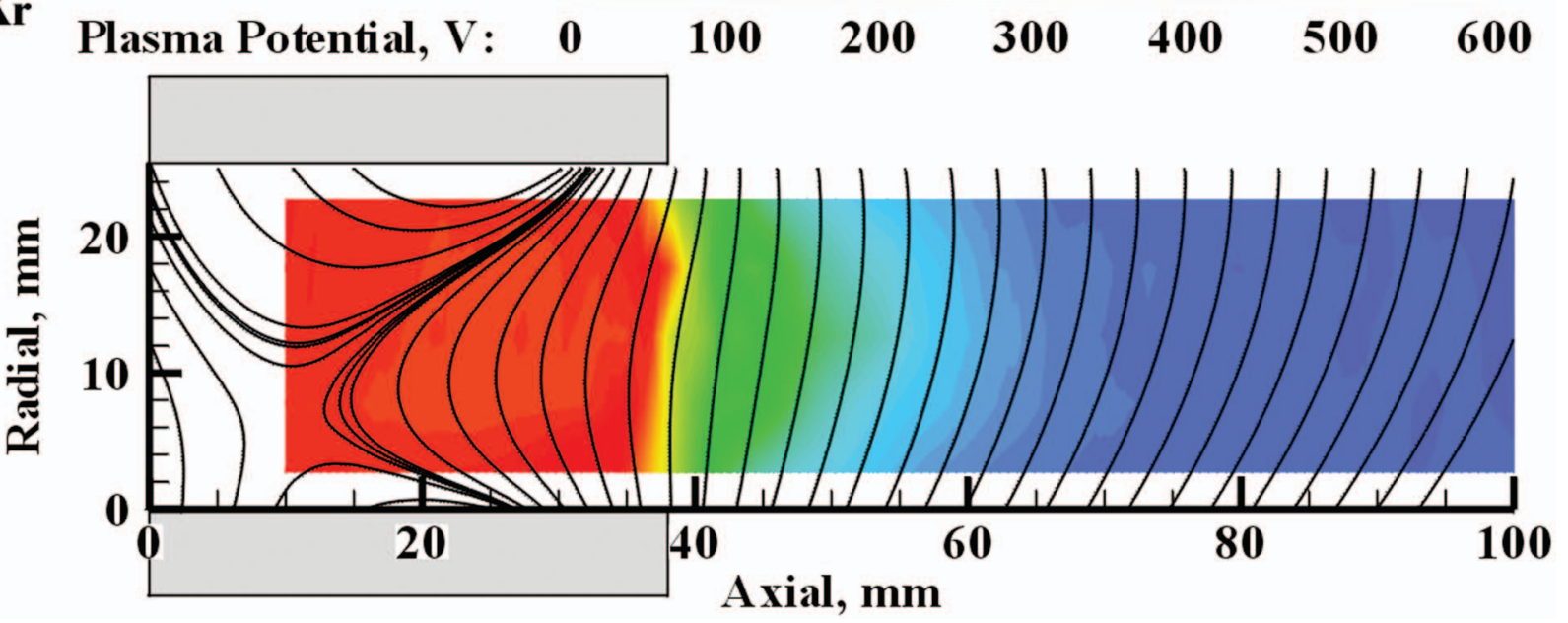

FIG. 12. (Color) Plasma potential map for xenon (a) and krypton (b) at a discharge voltage of $600 \mathrm{~V}$.

sults in strong focusing for the xenon case and defocusing in the krypton case. Interestingly, the $600-\mathrm{V}$ case also shows a weak "plasma jet" behavior that has also been observed by Haas. ${ }^{9}$ This behavior is visible in the area downstream of the main acceleration zone where the magnetic-field path lines are slightly convex.

Figure 13 shows the electron temperature map for the $600-\mathrm{V}$ cases. The same high electron temperature regimes exist in the $600-\mathrm{V}$ case as in the $500-\mathrm{V}$ case, although the anode "heating" zone is not captured in the 600-V krypton data. In the xenon case, the maximum electron temperature is about $47 \mathrm{eV}$. In the krypton case, the maximum electron temperature is between 50 and $60 \mathrm{eV}$ in most of the discharge channel, although there is an unusual "hot spot" on the inner discharge channel wall that reaches $85 \mathrm{eV}$. The electron temperature on the inner wall is extremely high, although given the relatively large error bars for electron temperature, this measurement is not unreasonable for highvoltage operation. With this said, the maximum electron temperature measured in the rest of the discharge channel is (a) $\mathbf{X e}$

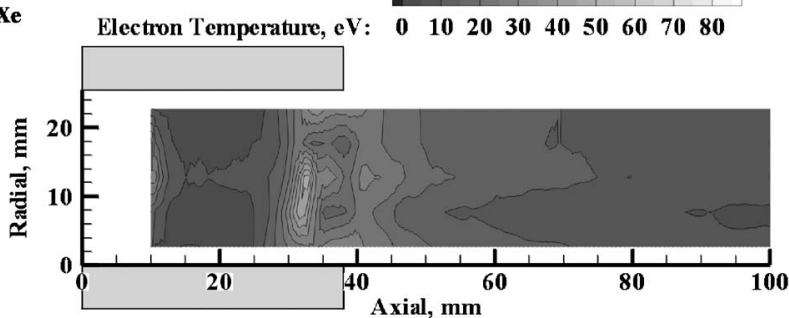

(b) $\mathbf{K r}$

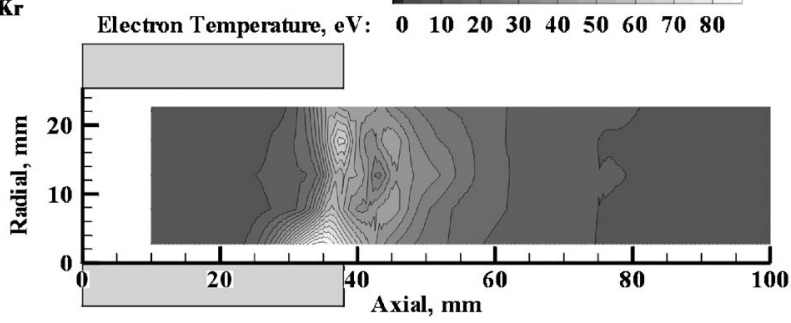

FIG. 13. Electron temperature map for xenon (a) and krypton (b) at a discharge voltage of $600 \mathrm{~V}$. 
(a) $\mathbf{X e}$

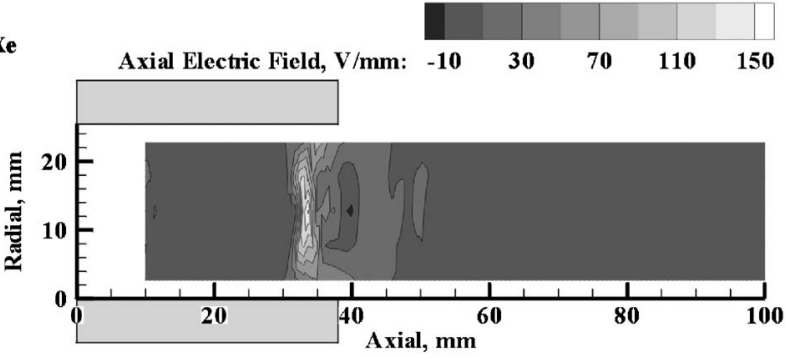

(b) $\mathbf{K r}$

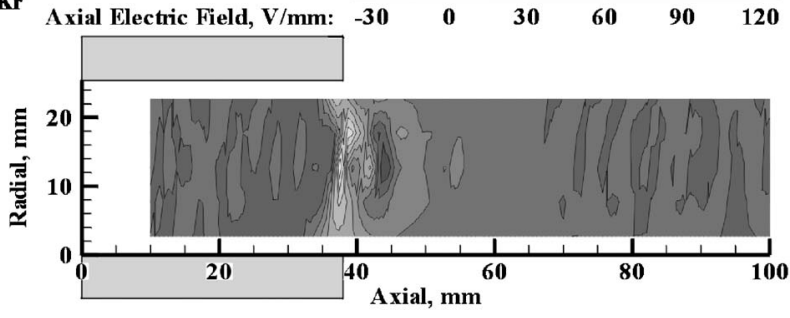

FIG. 14. Axial electric-field map for xenon (a) and krypton (b) at a discharge voltage of $600 \mathrm{~V}$.

probably more representative of the true electron temperature. The high electron temperature regions are similar in dimension for the xenon and krypton cases, although the krypton case is located slightly farther downstream. The fact that the maximum electron temperatures are similar in the $600-\mathrm{V}$ and the $500-\mathrm{V}$ cases is expected since the electron temperature is anticipated to saturate near $50-60 \mathrm{eV}$ due to discharge channel wall interactions. ${ }^{11,12,38,39}$

The axial and radial electric fields are shown in Figs. 14 and 15, respectively. Figure 14 clearly illustrates that krypton's acceleration zone is longer and located farther downstream than the xenon case. The maximum axial electric fields are 150 and $115 \mathrm{~V} / \mathrm{mm}$ in the xenon and krypton cases, respectively. Also visible in Fig. 14 is the potential well located between the axial locations of 40 and $45 \mathrm{~mm}$.

(a) $\mathbf{X e}$
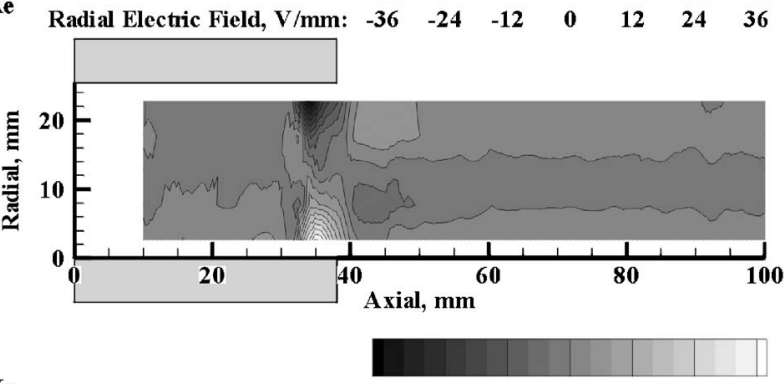

(b) $\mathbf{K r}$

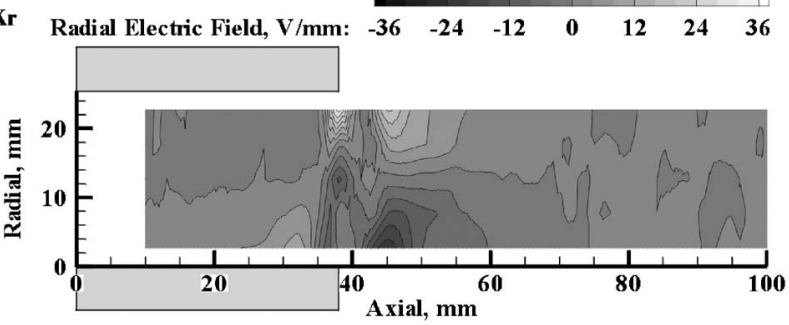

FIG. 15. Radial electric-field map for xenon (a) and krypton (b) at a discharge voltage of $600 \mathrm{~V}$.
TABLE II. Acceleration zone dimensions.

\begin{tabular}{|c|c|c|c|c|c|c|}
\hline $\begin{array}{c}\text { Point } \\
\text { no. }\end{array}$ & Propellant & $\begin{array}{c}V_{d} \\
(\mathrm{~V})\end{array}$ & $\begin{array}{l}\text { Avg. } \\
\text { length } \\
(\mathrm{mm})\end{array}$ & $\begin{array}{l}\text { Avg. } \\
\text { start } \\
(\mathrm{mm})\end{array}$ & $\begin{array}{l}\text { Avg. } \\
\text { end } \\
(\mathrm{mm})\end{array}$ & $\begin{array}{c}\text { Potential } \\
\text { drop } \\
\text { outside }(\%)\end{array}$ \\
\hline 1 & Xenon & 500 & 17.3 & 33.8 & 51.2 & 51.7 \\
\hline 2 & Xenon & 600 & 15.1 & 32.4 & 47.5 & 39.3 \\
\hline 3 & Krypton & 500 & 19.9 & 35.5 & 55.4 & 70.5 \\
\hline 4 & Krypton & 600 & 22.2 & 37.0 & 59.2 & 83.9 \\
\hline
\end{tabular}

The radial electric fields shown in Fig. 15 demonstrate the strong focusing and defocusing seen in the xenon and krypton cases, respectively. The maximum radial electric field is $36 \mathrm{~V} / \mathrm{mm}$ for the xenon case and $28 \mathrm{~V} / \mathrm{mm}$ in the krypton case, which are both greater than $20 \%$ of the maximum axial electric field. The maximum radial electric field is just upstream of the discharge channel exit in the xenon case and begins at the exit for the krypton case. Accordingly, severe wall erosion and wall losses are not expected due to this krypton defocusing.

\section{Acceleration zone dimensions}

For the operation points given in Table I, the average acceleration zone start, end, lengths, and the percent of ion acceleration outside the thruster are given in Table II. The acceleration zone start is defined as the point at which $90 \%$ of the potential drop remains; the acceleration zone end is the point at which $10 \%$ of the acceleration drop remains. The average is calculated by taking the mean of the five radial probe sweeps. The krypton acceleration zone begins between 1.7 and $4.6 \mathrm{~mm}$ farther downstream of the corresponding xenon points for the 500 and $600-\mathrm{V}$ cases, respectively. Also, the krypton acceleration length is 1.9 and $7.1 \mathrm{~mm}$ longer for krypton in the 500 and $600-\mathrm{V}$ cases, respectively. Although both xenon and krypton have a significant portion of their acceleration outside the discharge channel, the acceleration zone with krypton extends much farther than the xenon acceleration zone. Since the krypton acceleration zone starts farther downstream, is longer, and is almost entirely located outside of the discharge channel, it is not surprising that krypton has a larger beam divergence than xenon., ${ }^{4,8}$ The krypton ions that are accelerated away from the discharge channel centerline will have less of a chance to collide with the channel wall and therefore will accelerate freely to high angles off thruster centerline.

The dispersion efficiency characterizes the effect of the spread in ion velocities in the Hall thruster plume and is given by the equation $\eta_{d}=\left\langle v_{a}\right\rangle^{2} /\left\langle v_{a}^{2}\right\rangle$. In this equation, $v_{a}$ represents the ion velocity. With a longer acceleration length, one might expect krypton to have a lower dispersion efficiency than xenon. However, retarding potential analyzer measurements indicate that krypton actually has a smaller spread in ion velocity than xenon cases. ${ }^{8}$ Since ion velocity dispersion is dictated by the ionization zone, this finding indicates that the majority of the krypton ionization must be occurring upstream of the acceleration zone, a result that has been shown by Langmuir probe measurements. ${ }^{24}$ 

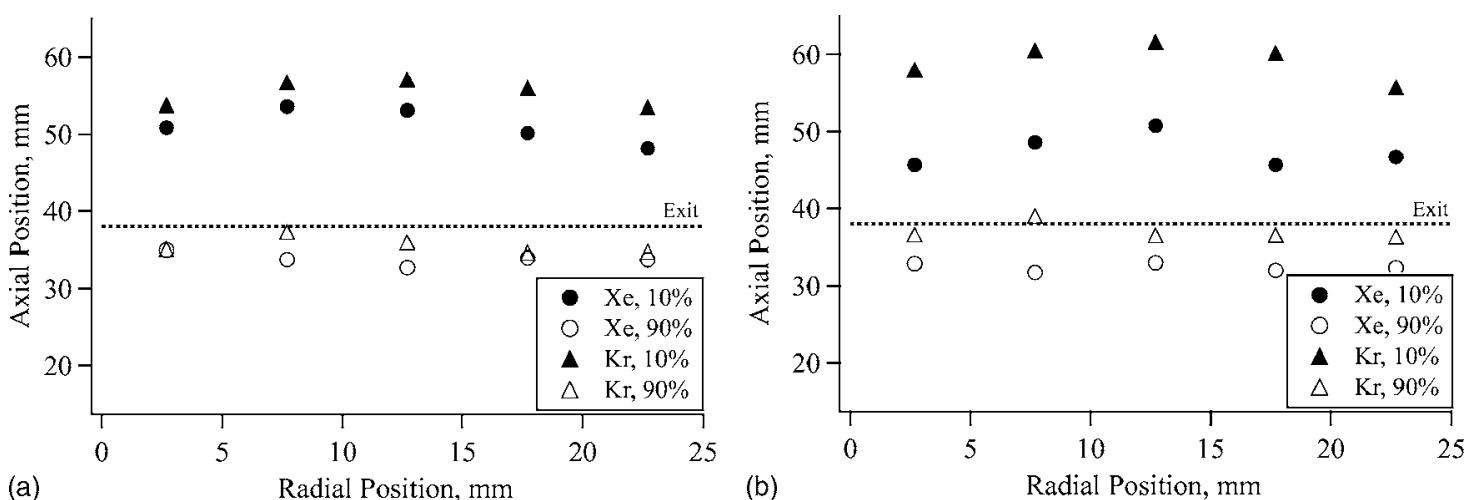

FIG. 16. Acceleration length for xenon and krypton at discharge voltages of (a) $500 \mathrm{~V}$ and (b) $600 \mathrm{~V}$.

The start and end of the acceleration zones for the 500and 600-V cases can be seen in Fig. 16. This figure illustrates krypton's longer acceleration length and that a large percentage of the acceleration zone appears outside of the discharge channel. Roughly speaking, the acceleration zone for krypton begins only slightly farther downstream of the corresponding xenon cases.

\section{CONCLUSIONS}

The internal plasma structure inside the NASA-173Mv1 has been successfully mapped for xenon and krypton operation. The plasma potential profile is shown to be well correlated with the magnetic-field path lines. In the xenon cases, the ions are focused toward the center of the discharge channel and in the krypton cases the ions are defocused. The maximum radial electric field in all of the xenon and krypton cases is equal to or greater than $20 \%$ of the maximum axial electric field. In addition, the acceleration zone is found to be longer and located further downstream for the krypton cases. These trends act to defocus the krypton ions and explain the larger beam divergence, which is an important contributing factor to the xenon-krypton efficiency gap.

Both propellants have high electron temperature regions that are similar in length and peak value. The high electron temperature region near the acceleration zone is located slightly farther downstream in the krypton cases. The maximum electron temperature is approximately $50-60 \mathrm{eV}$ for krypton and xenon at both 500 and $600 \mathrm{~V}$.

The defocusing of the ions is attributed to krypton's magnetic-field topology, which is optimized with a much different magnetic-field topology than the corresponding xenon conditions. Krypton optimization is centrally focused on propellant utilization optimization, and for this reason other efficiency components (such as beam divergence) suffer. There is a complicated coupling between beam divergence and propellant utilization that should be a focus of future study and raises the question of what can be done to design a krypton Hall thruster to optimize for both propellant utilization and ion beam focusing.

\section{ACKNOWLEDGMENTS}

We would like to thank the Association Francois-Xavier Bagnoud for their financial support during J.L.'s graduate studies and NASA Glenn Research Center for financial support through research grant No. NCC04GA38G (grant monitor David Jacobson).

${ }^{1}$ C. Marrese, J. M. Haas, M. T. Domonkos, A. D. Gallimore, S. Tverdokhlebov, and C. E. Garner, Proceedings of the 32nd AIAA/ASME/SAE/ ASEE Joint Propulsion Conference, Lake Buena Vista, FL, July 1-3, 1996 (American Institute of Aeronautics and Astronautics, Reston, VA, 1996), AIAA-96-2969.

${ }^{2}$ V. Kim, G. Popov, V. Kozlov, A. Skrylnikov, and D. Grdlichko, Proceedings of the 27th International Electric Propulsion Conference, Pasadena, CA, October, 2001 (Electric Rocket Propulsion Society, Cleveland, OH, 2001), 2001-065.

${ }^{3}$ A. V. Semenkin and G. O. Gorshkov, Proceedings of the 24th International Electric Propulsion Conference, September, 1995 (Electric Rocket Propulsion Society, Cleveland, OH, 1995), 1995-078.

${ }^{4}$ A. I. Bugrova, A. S. Lipatov, A. I. Morozov, and L. V. Solomatina, Plasma Phys. Rep. 28, 1032 (2002).

${ }^{5}$ A. I. Bugrova, A. S. Lipatov, A. I. Morozov, and D. V. Churbanov, Tech. Phys. Lett. 28, 821 (2002).

${ }^{6}$ D. T. Jacobson and D. H. Manzella, Proceedings of the 39th AIAA/ASME/ SAE/ASEE Joint Propulsion Conference, Huntsville, AL, July 20-23, 2003 (American Institute of Aeronautics and Astronautics, Reston, VA, 2003), AIAA-2003-4550.

${ }^{7}$ P. Y. Peterson, D. T. Jacobson, D. H. Manzella, and J. W. John, Proceedings of the 41st AIAA/ASME/SAE/ASEE Joint Propulsion Conference, Tucson, AZ, 10-13 July, 2005 (American Institute of Aeronautics and Astronautics, Reston, VA, 2005), AIAA-2005-4243.

${ }^{8}$ J. A. Linnell and A. D. Gallimore, "Efficiency analysis of a Hall thruster operating with krypton and xenon," J. Propulsion Power (to be published).

${ }^{9}$ J. M. Haas and A. D. Gallimore, Phys. Plasmas 8, 652 (2001).

${ }^{10}$ N. B. Meezan, W. A. Hargus, and M. A. Cappelli, Phys. Rev. E 63, 026410 (2001).

${ }^{11}$ Y. Raitses, D. Staack, A. Smirnov, and N. J. Fisch, Phys. Plasmas 12, 073507 (2005)

${ }^{12}$ Y. Raitses, D. Staack, M. Keidar, and N. J. Fisch, Phys. Plasmas 12, 057104 (2005).

${ }^{13}$ D. Staack, Y. Raitses, and N. J. Fisch, Appl. Phys. Lett. 84, 3028 (2004).

${ }^{14}$ J. A. Linnell and A. D. Gallimore, Proceedings of the 41st AIAA/ASME/ SAE/ASEE Joint Propulsion Conference, Tucson, AZ, July 10-13, 2005 (American Institute of Aeronautics and Astronautics, Reston, VA, 2005), AIAA-2005-4402.

${ }^{15}$ J. A. Linnell and A. D. Gallimore, J. Propul. Power 22, 921 (2006).

${ }^{16}$ R. R. Hofer, "Development and characterization of high-efficiency, highspecific impulse xenon Hall thrusters," Doctoral thesis, University of Michigan (2004).

${ }^{17}$ R. R. Hofer, R. S. Jankovsky and A. D. Gallimore, J. Propul. Power 22, 721 (2006).

${ }^{18}$ R. R. Hofer, R. S. Jankovsky, and A. D. Gallimore, J. Propul. Power 22, 732 (2006).

${ }^{19}$ V. Kim, J. Propul. Power 14, 736 (1998).

${ }^{20}$ R. R. Hofer and A. D. Gallimore, Proceedings of the 38th AIAA/ASME/ SAE/ASEE Joint Propulsion Conference, Indianapolis, IN, July 7-10, 2002 
(American Institute of Aeronautics and Astronautics, Reston, VA, 2002), AIAA-2002-4111.

${ }^{21}$ V. M. Gavryshin, V. Kim, V. I. Kozlov, and N. A. Maslennikov, Proceedings of the 24th International Electric Propulsion Conference, Moscow, Russia, September 19-23, 1995 (Electric Rocket Propulsion Society, Cleveland, OH, 1995), IEPC-1995-038.

${ }^{22}$ A. I. Morozov, Sov. Phys. Dokl. 10, 775 (1966).

${ }^{23}$ A. I. Bugrova, A. I. Morozov, G. B. Popkov, and V. K. Kharchevnikov, Sov. Phys. Tech. Phys. 31, 2 (1986).

${ }^{24} \mathrm{~J}$. A. Linnell and A. D. Gallimore, Proceedings of the 42nd AIAA/ASME/ SAE/ASEE Joint Propulsion Conference, Sacramento, CA, July 9-12, 2006 (American Institute of Aeronautics and Astronautics, Reston, VA, 2006), AIAA-2006-4470.

${ }^{25}$ A. I. Morozov, Y. V. Esinchuk, G. N. Tilinin, A. V. Trofimov, Y. A. Sharov, and G. Y. Shchepkin, Sov. Phys. Tech. Phys. 17, 38 (1972).

${ }^{26}$ J. M. Haas, "Low-perturbation interrogation of the internal and near-field plasma structure of a Hall thruster using a high-speed probe positioning system," Doctoral thesis, University of Michigan (2001).

${ }^{27}$ J. M. Haas, A. D. Gallimore, K. McFall, and G. Spanjers, Rev. Sci. Instrum. 71, 4131 (2000).
${ }^{28}$ N. Hershkowitz and M. H. Cho, J. Vac. Sci. Technol. A 6, 2054 (1988).

${ }^{29}$ C. H. Reinsche, Numer. Math. 10, 177 (1967).

${ }^{30}$ G. D. Hobbs and J. A. Wesson, Phys. Plasmas 9, 85 (1967).

${ }^{31}$ T. Intrator, M. H. Cho, E. Y. Wang, N. Hershkowitz, D. Diebold, and J. DeKock, J. Appl. Phys. 64, 2927 (1988).

${ }^{32}$ L. Dorf, Y. Raitses, and N. J. Fisch, Rev. Sci. Instrum. 75, 1255 (2004). ${ }^{33}$ L. A. Schwager, Phys. Fluids B 5, 631 (1993).

${ }^{34}$ M. Keidar, I. D. Boyd, and I. I. Beilis, Phys. Plasmas 8, 5315 (2001).

${ }^{35}$ M. Keidar and I. D. Boyd, Appl. Phys. Lett. 87, 121501 (2005).

${ }^{36}$ R. R. Hofer and A. D. Gallimore, Proceedings of the 28th International Electric Propulsion Conference, Toulouse, France, March 17-21, 2003 (Electric Rocket Propulsion Society, Cleveland, OH, 2003), IEPC-2003037.

${ }^{37}$ Y. Raitses, D. Staack, L. Dorf, and N. J. Fisch, Proceedings of the 39th Joint Propulsion Conference, Huntsville, AL, July, 2003 (American Institute of Aeronautics and Astronautics, Reston, VA, 2003), 2003-5153.

${ }^{38}$ E. Ahedo and D. Escobar, J. Appl. Phys. 96, 983 (2004).

${ }^{39}$ S. Barral, K. Makowski, Z. Peradzyski, N. Gascon, and M. Dudeck, Phys. Plasmas 10, 4137 (2003). 